\title{
Proposed Socio-Environmental Design Factors (SEDEF) Model As Residential Neighbourhood Crime Prevention Strategy In Nigeria.
}

\author{
Sunday Emmanuel Olajide \\ Department of Real Estate \\ Faculty of Technology Management \& Business \\ Universiti Tun Hussein Onn Malaysia. \\ Mohd Lizam \\ Department of Real Estate \\ Faculty of Technology Management \& Business \\ Universiti Tun Hussein Onn Malaysia.
}

\begin{abstract}
Housing is considered essential human need as it is ranked next to food for obvious reasons like provision of living accommodation, investment opportunities, social and recreation services among others. However, its relevance to humanity is gradually being eroded as a result of the threat from residential neighbourhood crime in the form of burglary and theft, vandalism, incivilities and street crime, robbery and even violent crime. In Nigeria, it was found that the use of penal system (use of police, prison and courts) for crime control is prevalent which researchers have described to be grossly inadequate. Hence, the intention of this research is to empirically analyse the desirability of the proposed socio-environmental design factors (SEDeF) model as a more effective technique to curb residential neighbourhood crime in Nigeria. One Thousand (1000) sets of structured questionnaire were administered on the residents of residential estates within the South Western States of Nigeria out of which 467 were considered useable after the data screening. Purposive and systematic sampling techniques were adopted while logistic regression was used to determine the impact of the various components of each factor. The results showed a significant probability of $\mathbf{0 . 0 0 0 7}$ and $\mathbf{0 . 0 0 2 5}$ for environmental design factors and social development factors respectively establishing the desirability of the model in residential neighbourhood crime prevention. The policy implication of this result is that if government can intensify effort in the use of social development factors (SDF) and environmental design factors (EDF), the soaring trend of residential neighbourhood crime would be curtailed.
\end{abstract}

Key words: Crime prevention; Logistic regression; Nigeria; Residential neighbourhood crime; SEDeF.

\section{INTRODUCTION}

Urbanization in Nigeria is said to be growing in an alarming rate and is also seen to be responsible for the high rate of residential neighborhood insecurity. Over the years, in order to curb the menace, the use of penal system (police, courts and prisons) has been predominantly adopted in Nigeria which studies found to be grossly inadequate (Sutton, et al. 2013; Van Dijk \& de Waard 1991).

Generally speaking, housing (residential developments) is ranked second (next to food) in the hierarchy of human needs simply because of its potentials like investment, accommodation, 
social and recreation and its contribution to the national economy (Agunbiade, 2012). However, residential neighourhood globally is being threatened by the social ill of property crime (burglary, street incivility, graffiti, robbery, and even violent crimes) which has its consequences in the forms of neighbourhood decline, reduced housing values, residential mobility, increased residents' budgets, reduced public revenue from property tax, increased government's budget, psychological effects of fear of crime to mention only but a view (Cohen, 1990, Gibbon, 2004). Efforts to curb this menace are seen to have been intensified in the developed worlds through the use of modern techniques and improved research. However, investigation revealed that Nigeria among other developing nations still rely predominantly on the use of penal system (police, courts and prisons) which researches found to be grossly inadequate, hence the need for a paradigm shift.

From the foregoing, due to the inability of the penal system which is prevalent in Nigeria to reasonably check property crime, this paper is poised to propose Socio-Environmental Design Factor (SEDeF) model as an alternative or at least a supplement to the penal system. This research was meant to empirically analyse the desirability of the proposed (SEDeF) model as a better alternative to the penal system within the Nigerian residential estates. SEDeF is derived from the two theories of crime prevention: Crime Prevention through Social Development (CPSD) and Crime Prevention Through Environmental Design (CPTED). Effort is made in the course of this study to analyse public perception on the desirability of the model to curb residential neighbourhood crime using logistic regression.

This research is set to enhance the sustainability of the residential environment, to boost housing investment, to remove psychological fear of crime and to increase public revenue towards a robust Gross Development Product (GDP).

\section{Nature of Residential Neighbourhood Crime}

\section{LITERATURE REVIEW}

The problem of crime has become a standard component in the discussion of urban issues and the control of crime is now as much an urban policy issue as in inadequate housing and poverty (Naroff \& Hellman, \& Skinner, 1980). It is essentially and gradually manifesting that these problems are interrelated. Property crime, especially in homes, is said to be badly affected.

The unlawful entry into other peoples' residential apartment for the purpose of committing a crime is referred to as 'residential burglary '(Moreto, 2010; Ratcliffe, 2001). Offences that constitute 'break and enter' include forceful entry into someone's house probably with an intention to steal. For the purpose of this research, residential burglary is used to refer to both break and enter-dwelling and stealing from dwelling offences. The fact that homes are usually left vacant during the day accounts for the frequent burglary offending. Many urban dwellers especially the high income class are mostly victimized due to their massive acquisition of personal effects (valuables) and the fact that a large number of detached dwelling with many accessible entry points like doors and windows (Grabosky, 1995) .

The cumulative effects of crime on the socio-economic reconstitution or concentration of particular groups, within neighbourhoods, play out over decades. However, changing levels of crime are likely to induce more immediate responses at the individual level. Increases in crime will directly impact an individual's perception of safety in a neighbourhood. In turn, as perceptions regarding the safety of one's own community deteriorate, urban residents often choose to move from impacted communities in search for a safer neighbourhood (Cullen, \& 
Levitt, 1999; Dugan, 1999; Tita, et.al 2006). Primarily, crime and fear of crime lead to flight from the city to the suburbs. It leaves in its wake areas of concentrated poverty and racial/ethnic enclaves in the urban core (Jargowsky, 1996; Massey \& Denton, 1993) .

As housing markets serve as the arena in which the impact of crime first manifests itself, these markets can potentially serve as early indicators of neighbourhood decline. Therefore, a more complete examination of how crime affects local housing prices will ultimately lead to a better understanding of the larger issue pertaining to small crime impacts on residential stability (Schwartz, et. al, 2003).

\section{Neighbourhood Crime landscape in Nigeria}

Increase in the crime rate in Nigeria was being reported as early as the eighties (Times International, London: November 4, 1985). Lives were no longer safe; the country was characterized by insecurity challenges posed by offenders. Essentially, urbanization and development of large cities were not new in Nigeria, but rather the crime surge is what is relatively recent. Nigeria, as a matter of fact, has over a century developed large towns and cities, but the reality of insecurity especially posed by criminals is relatively recent. The crime wave and the extent of violence in Nigeria are becoming more frequent, more offensive and horrendous. There are daily reports of more violent crimes (Agbola, 1997; Fabiyi, 2004).

The unexpected rise in urban insecurity has been associated to aggravated poverty that has become entrenched in most urban centers of many African nations. Population in poverty has been growing steadily in Nigeria, for example, in 1985, 27.2 percent of Nigerians were rated as poor; in 1990, it was measured as 56 percent; in 2000, it was estimated to be about 66 percent and in 2014, Nigeria was classified as the third poorest country in the world (Federal Office of Statistics, Nigeria, 1999; World Bank, 1999; 2000; and 2014). Both insecurity and poverty function in a symbiotic way to make life in most Nigerian urban cities very irritable and relatively irksome. Fabiyi (2004) also observed another major cause of the increased wave of crime in Nigeria as the 1966/1970 civil war as he opined that the civil war taught Nigerians how to kill themselves with impunity, to have little regard for human life and to derive joy in shedding blood. The official security apparatus in Nigeria grossly fails to checkmate the security problems in Nigeria. This is due primarily to inadequate facilities to fight crime efficiently and due to the poverty level that has brought uncontrolled corruption within the security systems (Agbola, 1997; Onibokun, 2003; Fabiyi, 2004).

Olufolabo, Akintande and Ekum (2015) identified eighteen (18) major categories of crimes associated with Nigerian urban centers; they posited that police department emphasized stealing/theft/burglary as the most committed crime in most cities. They went further to mention illiteracy, broken home, bad company, porous environment and failure of police and other judicial authorities in administering justice as main causes of residential urban crime.

\section{Thrust of Socio-Environmental Design Factors (SEDeF) Model}

The model was derived from two neighborhood crime prevention theories. These are Crime Prevention through Social Development (CPSD) and Crime Prevention through Environmental Design (CPTED). CPSD dwells on the philosophy that if the social risk factors (poverty, illiteracy, unemployment, poor parenting and homelessness among others) which are regarded as the root causes of crime are tenaciously tackled, that it is capable of stemming down criminal tendencies. Researches had supported it that poverty, illiteracy, unemployment, homelessness and poor parenting are capable of influencing criminal tendencies (The John 
Howard Society of Alberta 1995; Hastings 2008; Waller and Weiler,1985). CPTED on the other hand opines that the tactical and purposeful manipulation of the residential neighborhood design is capable of discouraging potential offenders to commit crime (Crowe, 1991; Cozens, 2014; Cozens \& Love, 2015). The key elements of CPTED include access control, surveillance, maintenance, target hardening and territoriality among others. These elements of CPTED visualize on a virtual house and neighborhood, that is, designing the residential environment with cognizance to effective maintenance, provision of natural (designed window and doors to control intruders), formal surveillance (police patrol) and mechanical surveillance (use of lighting and CCTV); creating sense of ownership and creating means of controlling the intruders. Crime opportunity theories upon which the two aforementioned theories are based were also considered.

The need for this model arises from recent studies on the soaring trend of neighborhood crime in Nigeria (Agbola, 1997; Sutton, 2013) vis-à-vis the primitive crime control approach of the penal system (use of police, judiciary and prison) adopted which studies have found to be grossly inadequate (Sutton, et al. 2013; Van Dijk \& de Waard 1991; Clarke,1980). Considering the grave consequences of neighborhood crime to the residents, properties within the vicinity and government, this research sees the need for a paradigm shift as a lofty consideration. The model is therefore proposed as an alternative or at least a supplement to the existing strategy (penal system). The research intended to measure the desirability of the social development factors and environmental design factors as neighborhood crime prevention techniques. Hence, this study attempts to measure public (residents - head of household) perception on the impact of social risk factors and environmental design factors on residential neighborhood crime.

The work of The John Howard Society of Alberta (1995) on crime prevention through social development actually encapsulated the measurement variables supported with empirical evidences. This work established the fact that poverty, unemployment, illiteracy, homelessness and poor parenting were capable of influencing potential offender to criminal activities. Likewise, Cozens and Love (2015) and Marzbali et. al. (2012) in their effort to reappraise the desirability of crime prevention through environmental design in controlling neighbourhood crime emphasized through empirical and practical proofs that proper implementation of the elements of CPTED (access control, territoriality, target hardening, surveillance and maintenance) were practically sufficient to curb residential neighborhood crime. For the purpose of emphasis, Armitage and Pascoe (2016) as well as Cozens and Love (2015) succinctly defined the elements of CPTED in the order below.

Design Concept of territorial reinforcement seeks to promote notions of proprietary concern and a "sense of ownership" in legitimate users of space, thereby reducing criminal opportunities by discouraging the presence of legitimate users. Surveillance on the other hand refers to the way a residential neighbourhood is designed to maximise the ability of formal (security guards, police, employees) or informal (residents, passerby, shoppers) users of the space to observe suspicious behaviour. This can be natural (design of windows and doors to monitor intruders), mechanical (use of CCTV) and also human (police and security control). Target hardening increases the effort and risk of offending and reduces the rewards associated with the commission to a crime and is long-established and traditional crime control prevention technique. Image/space management seeks to promote a positive image and routine maintenance of the built environment to ensure the continued effective functioning of the physical environment and this also transmits positive signals to all users. The CPTED concept of using spatial definition to deny access to potential targets is known as natural 
access control and is focused on reducing opportunities for crime by creating a heightened perception of risk in offenders. Legitimate activity support uses design and signage to encourage acceptable behaviour in the usage of public space and places "unsafe" activities (such as those involving money transactions) in "safe" locations (those with high levels of activity and with surveillance opportunities)

However, the researchers did not spare the fact that these strategies were to be frequently reappraised in order to meet the demands of contemporary challenges (Clarke, 1992).

\section{METHODOLOGY}

Logistic regression analysis was used to predict the desirability of Socio-Environmental Design Factor (SEDeF) model as a supplement to the penal system which was predominantly used in Nigeria as residential neighbourhood crime prevention technique which researches have found to be grossly inadequate (Sutton et.al 2013). A total of 1000 sets of questionnaire was randomly distributed to the residents (head of household) of selected residential neighbourhoods within the Southern-Western Nigeria. Out of the 1000 sets of questionnaire administered, 728 were retrieved and after the data screening (missing data, outliers and multicollinearity), only 467 sets of questionnaire were found to be clean data and as such were subsequently used for the analysis of this research. Purposive and stratified multi-stage sampling techniques were adopted in the selection of the residential estates as well as the residential buildings from which the heads of the household were used to respond to the questionnaire.

As regards the variable used for the analysis, the independent variables were chosen from the elements of the social risk factors and the environmental design factors. For the dependent varable, residential neighbourhood crime, separate logistic analyses were carried out in both cases through dichotomous coded dependent variable which was whether or not the elements of both social risk factors (poverty, homelessness, unemployment, illiteracy and family disintegration) and the environmental design factors (territorial functioning, natural access, target hardening, surveillance, image management and maintenance) influence residential neighbourhood crime. Content validity was adopted to ascertain the appropriateness of the research instrument.

Pallant (2011) highlighted the benefits and desirability of logistic regression. According to her, logistic regression allows for assessment of how well one's set of predictor-variables predicts or explains one's categorical dependent variable. It gives an indication of the adequacy of the model (set of predictor variables) by assessing "goodness of fit". It also provides an indication of the relative importance of each predictor variable or the interaction among the predictor variables. It provides a summary of the accuracy of the classification of cases based on the mode, allowing the calculation of the sensitivity and specificity of the model and the positive and negative predictive values. Pallant (2011) added that though logistic regression does not take assumption concerning the distribution of scores for the predictor variables; however, it is said to be sensitive to high correlations among the predictor variables (multicollinearity). Outliers as well could influence the results of logistic regression. All these were painstakingly noted and avoided in order to present a reliable result.

\section{DATA ANALYSIS}

According to Pyke and Sheridan (1993), when the dependent variable in an attrition study is dichotomous, logistic regression, as opposed to either multiple regression or discriminant 
analysis, is particularly appropriate (Hosmer and Lemeshow, 2000). Like multiple regression, logistic regression analysis can be used to determine which independent variables and interaction are required to describe satisfactorily attrition. Logistic analysis also provides predicted probabilities of retention for combination of the independent variables.

The logistic regression procedure utilized automatically creates new variables for categorical variables. This obviates the necessity of creating "dummy variables" as in multiple linear regression (Cleves and Tosetto, 2000). In the present study, the coding scheme utilized for the creation of new variables was indicator coding. With indicator coding, the coefficients for the new variables represent the effect of each category compared to a reference category. The regression equation was built with forward, stepwise entry, using the computationally more intensive likelihood-ratio (LR) test, rather than the Wald statistic, as the criterion for determining variables to be removed from the model (Hauck \& Donner, 1977; Jennings, 1986). Stepwise regression provides a useful and effective means of studying outcomes which have received little prior attention or are unknown (Draper \& Smith, 1981). P-in was set at 0.05 and g-out at 0.10 in order to identify as many possible associations to retention as possible. Following Hosmer and Lemeshow (2000), the following procedure was utilized for selection of significant independent variables and interactions: (1) Stepwise selection of main effects; (2) forced entry of the main effects significant on step (1), followed by stepwise selection of interaction terms given the main effects variables in the model; and (3) assessment of the final model through examination of goodness-of-fit statistics.

Logistic regression was used to formulate two empirical models describing the attrition patterns of the socio-environmental design factors model. The separate models generated for environmental design factors and social risk factors are discussed below.

There are two hypotheses that existed in the analysis:

H1: There is a significant impact of the environmental design factors on the residential neighbourhood crime.

H2: There is a significant impact of the social risk factors on residential neighbourhood crime.

The implication of $\mathrm{H} 1$ is to measure the contribution of each of the elements of the environmental design factors (Territorial reinforcement (RNCEDF1); Natural surveillance (RNCEDF2); Natural access control (RNCEDF3); Space Management (RNCEDF4); and target hardening (RNCEDF5) on the neighbourhood crime and finally to measure the general impact of the environmental design factors as a whole on the residential neighbourhood crime (R2).

On the other hand, the implication of $\mathrm{H} 2$ is also to measure the contribution of each of the elements of the social risk factors: homelessness (RNCSRF1); Illiteracy (RNCSRF2); poverty (RNCSRF3); Unemployment (RNCSRF4); and Family disintegration (RNCSRF5)) on the neighbourhood crime and finally to measure the aggregate impact of the social risk factors on the residential neighbourhood crime.

Analysis of $\mathrm{H} 1$ is demonstrated in the next section of this report: 
Table 1: Logistic regression of the Environmental Design Factors (EDF) and Residential Neighbourhood Crime (RNC).

\begin{tabular}{|c|c|c|c|c|c|c|}
\hline RNCAware & Odd Ratio & Std. Error & (z) & $\mathrm{P}>(\mathrm{z})$ & $95 \%$ Conf. & Interval \\
\hline RNCEDF1 & 1.93427 & .8216945 & 1.55 & 0.120 & .8412387 & 4.447488 \\
\hline RNCEDF2 & 2.405872 & .9625308 & 2.19 & 0.028 & 1.098316 & 5.270084 \\
\hline RNCEDF3 & 3.154085 & 1.259312 & 2.88 & 0.004 & 1.44218 & 6.898067 \\
\hline RNCEDF4 & 2.158549 & .9752628 & 1.70 & 0.089 & .8903837 & 5.232952 \\
\hline RNCEDF5 & 2.500331 & .9302861 & 2.46 & 0.014 & 1.205855 & 5.184417 \\
\hline _cons & .3797542 & .3029378 & -1.21 & 0.225 & .0795209 & 1.813526 \\
\hline Model 1 & \multicolumn{6}{|c|}{ 0.6597RNCEDF1+0.8779 RNCEDF2+1.1487 RNCEDF3+0.7694 RNCEDF4+0.9164 RNCEDF5-09682 } \\
\hline \multicolumn{2}{|c|}{ Number of observation } & \multicolumn{5}{|l|}{467} \\
\hline \multicolumn{2}{|l|}{ Chi Square } & \multicolumn{5}{|l|}{21.28} \\
\hline \multicolumn{2}{|l|}{ P-Value } & \multicolumn{5}{|l|}{0.0007} \\
\hline \multicolumn{2}{|l|}{$\mathrm{R}^{2}$} & \multicolumn{5}{|l|}{0.2808} \\
\hline
\end{tabular}

The likelihood ratio chi-square of $21.28, \mathrm{R} 2$ of 0.2808 with a p-value of 0.0007 tells us that our model as a whole fits significantly better than an empty model (i.e., a model with no predictors). That is, there exists statistical evidence against the null hypothesis. It is a measure of goodness of fit.

In the table 1 we see the coefficients, their standard errors, the z-statistic, associated p-values, and the 95\% confidence interval of the coefficients. RNCEDF2, RNCEDF3, and RNCEDF5 are statistically significant. The logistic regression coefficients give the change in the log odds of the outcome for a unit increase in the predictor variable.

For every one unit change in RNCEDF1, the log odds of existence of RNC (versus non-existence) increases by 0.6597 . For a one unit increase in RNCEDF2, the log odds of existence of RNC (versus non-existence) increases by 0.8779 . For a one unit increase in RNCEDF3, the log odds of existence of RNC (versus non-existence) increases by 1.1487. For a one unit increase in RNCEDF4, the log odds of existence of RNC (versus non-existence) increases by 0.7694 . For a one unit increase in RNCEDF5, the log odds of existence of RNC (versus non-existence) increases by 0.9164 .

It can be summarily deduced that for a one unit increase in RNCEDF1, the odds of existence of RNC (versus non-existence) increase by a factor of 1.93. For a one unit increase in RNCEDF2, the odds of existence of RNC (versus non-existence) increase by a factor of 2.41. For a one unit increase in RNCEDF3, the odds of existence of RNC (versus non-existence) increase by a factor of 3.15. For a one unit increase in RNCEDF4, the odds of existence of RNC (versus nonexistence) increase by a factor of 2.16. And for a one unit increase in RNCEDF5, the odds of existence of RNC (versus non-existence) increase by a factor of 2.50 .

Analysis of $\mathrm{H} 2$ is demonstrated in the next section of this report: 
Olajide, S.E. \& Lizam, M. (2017). Proposed Socio-Environmental Design Factors (SEDEF) Modelas Residential Neighbourhood Crime Prevention Strategy in Nigeria. Advances in Social Sciences Research Journal, 4(1) 203-214.

Table 2: Logistic regression of the Social Risk Factors (SRF) and Residential Neighbourhood Crime (RNC).

\begin{tabular}{|c|c|c|c|c|c|c|}
\hline RNCAware & Odd Ratio & Std. Error & (z) & $\mathrm{P}>(\mathrm{z})$ & $95 \%$ Conf. & Interval \\
\hline RNCSRF1 & 1.556758 & 1.010764 & 0.68 & 0.495 & .4360712 & 5.557569 \\
\hline RNCSRF2 & 2.354857 & .9347409 & 2.16 & 0.031 & 1.081651 & 5.126747 \\
\hline RNCSRF3 & 2.640727 & 1.055058 & 2.43 & 0.015 & 1.206814 & 5.778389 \\
\hline RNCSRF4 & 2.006081 & .9002344 & 1.55 & 0.121 & .8324713 & 4.834232 \\
\hline RNCSRF5 & 2.668418 & 9920691 & 2.64 & 0.008 & 1.287635 & 5.529871 \\
\hline cons & .495619 & .4742667 & -0.73 & 0.463 & .0759658 & 3.233538 \\
\hline Model 2 & $0.4426 \mathrm{RNCSR}$ & $+0.8565 \mathrm{RNC}$ & +0.9710 & +0.6962 & $4+0.9818 \mathrm{RNC}$ & $5-0.7019$ \\
\hline \multicolumn{2}{|c|}{ Number of observation } & \multicolumn{5}{|l|}{467} \\
\hline \multicolumn{2}{|c|}{ Chi Square } & \multicolumn{5}{|l|}{18.42} \\
\hline \multicolumn{2}{|l|}{ P-Value } & \multicolumn{5}{|l|}{0.0025} \\
\hline \multicolumn{2}{|l|}{$\mathrm{R}^{2}$} & \multicolumn{5}{|l|}{0.2699} \\
\hline
\end{tabular}

For every one unit change in RNCSRF1, the log odds of existence of RNC (versus non-existence) increases by 0.4426 . For a one unit increase in RNCSRF2, the log odds of existence of RNC (versus non-existence) increases by 0.8565 . For a one unit increase in RNCSRF3, the log odds of existence of RNC (versus non-existence) increases by 0.9710. For a one unit increase in RNCSRF4, the log odds of existence of RNC (versus non-existence) increases by 0.6962 . For a one unit increase in RNCSRF5, the log odds of existence of RNC (versus non-existence) increases by 0.9815

For a one unit increase in RNCSRF1, the odds of existence of RNC (versus non-existence) increase by a factor of 1.5568. For a one unit increase in RNCSRF2, the odds of existence of RNC (versus non-existence) increase by a factor of 2.3548. For a one unit increase in RNCSRF3, the odds of existence of RNC (versus non-existence) increase by a factor of 2.6407. For a one unit increase in RNCSRF4, the odds of existence of RNC (versus non-existence) increase by a factor of 2.0061. And for a one unit increase in RNCSRF5, the odds of existence of RNC (versus nonexistence) increase by a factor of 2.6684 .

Here we examine the predictive ability of the model:

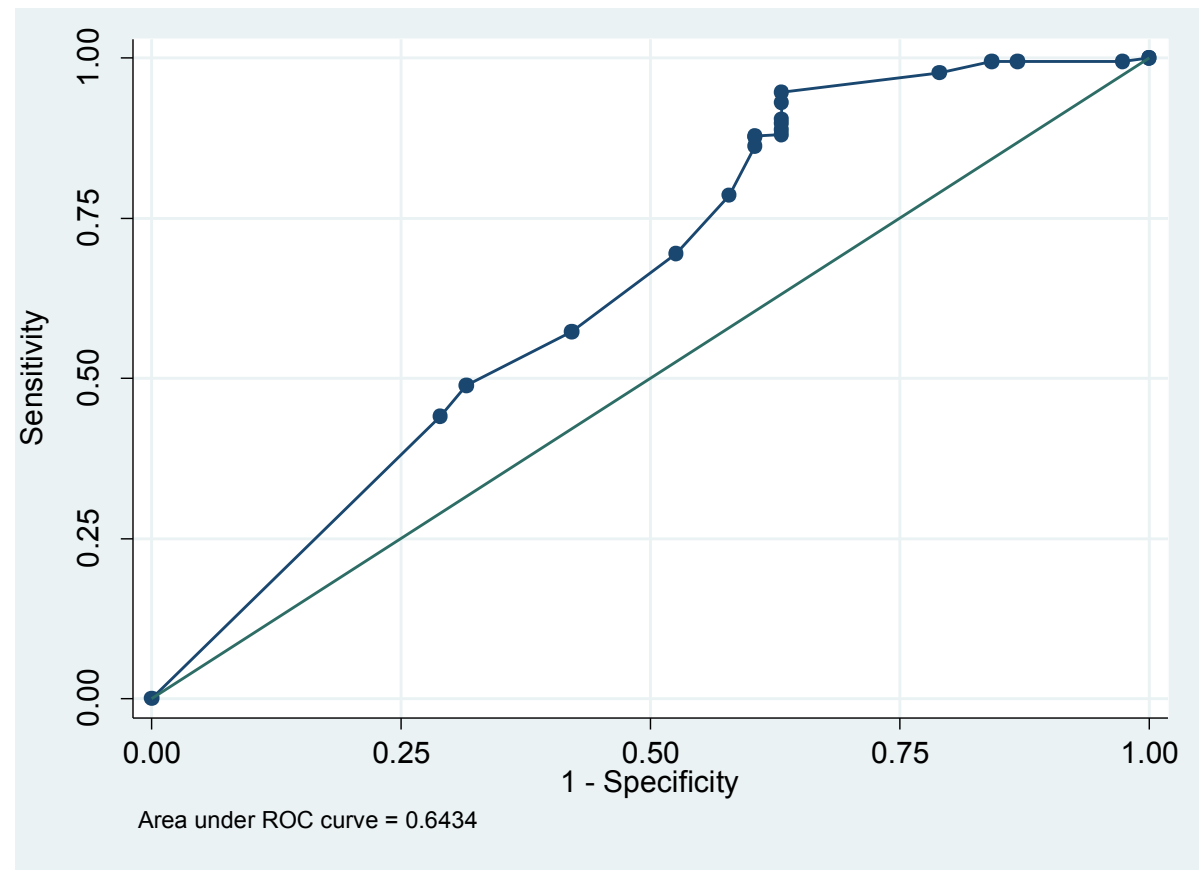

Figure 1: Showing the predictive ability of the models 


\section{Number of observations $=\quad 467$, Area under ROC curve $=0.6434$}

The interpretation is that the model has approximately $64 \%$ predictive ability which is statistically moderate and acceptable (Archer and Lemeshow, 2006) .

\section{DISCUSSION ON RESEARCH FINDINGS}

The inferences from the two (2) models generated in the analysis could be summarised as follows:

Model 1 (Environmental Design Factors) in line with the formulated hypothesis that the environmental design factors are capable of influencing residential neighbourhood crime is hereby supported with the aggregate P-Value showing 0.0007 which is quite less than the goodness of fit set at $\leq 0.05$ (Archer and Lemeshow, 2006). This is in line with the research conducted by Abdullah, et al, (2012), Cozens and Love, (2015) Armitage and Pascoe (2016) where it was affirmed that application of the principles of crime prevention through environmental design is desirable in neighbourhood crime was validated.

However, considering the predictive contribution of the various elements of the environmental design model, only three elements, natural access (0.004), target hardening (0.014) and natural surveillance $(0.028)$ were found to be statistically significant. This can be further interpreted that while implementing the concept of environmental design as neighbourhood crime prevention technique, emphasis should be placed on natural access, target hardening and natural surveillance as the results showed that from the public opinion they are seen to be contributing more to the model.

Model 2 (Social Risk Factors) in line with the formulated hypothesis that the social risk factors are capable of influencing residential neighbourhood crime is hereby supported with the aggregate P-Value showing 0.0025 which is quite less than the goodness of fit set at $\leq 0.05$ (Archer and Lemeshow, 2006). This is in line with the research conducted by Ross et., al (2011); Grattaglioano et. al (2015) and Ngutu (2014) where it was affirmed that application of the principles of crime prevention through social development is desirable in neighbourhood crime was validated.

However, considering the predictive contribution of the various elements of the social development model, only three elements, poverty $(0.031)$, illiteracy $(0.015)$ and family disintegration (0.008) were found to be statistically significant. This can be further interpreted that while implementing the concept of social development as neighbourhood crime prevention technique emphasis should be placed on poverty, education and juvenile delinquency as the results showed that from the public opinion they are seen to be contributing more to the model.

\section{CONCLUSIONS}

The intention of this research was to seek and analyse public perception about the desirability of supplementing if not substituting the Socio-Environmental Design Factors (SEDeF) model with the prevailing penal system (predominant use of police, courts and prisons) to checkmate residential neighbourhood crime in Nigeria. This led to the proposition of two hypotheses that Social risk factors as well as environmental design factors are able to influence residential neighbourhood crime. The results of the analyses supported the alternative hypotheses that both the social risk factors and environmental design factors are capable of substantially 
influencing residential neighbourhood crime. The implication of these results is that every effort made on social development programmes and deliberate intention to manipulate residential neighbourhood through purposeful design is a laudable effort towards controlling or preventing residential neighbourhood crime.

However, to enhance effective implementation of the model, the Nigerian government has some roles to play in the area of combating poverty, homelessness, illiteracy, unemployment and juvenile delinquencies through social development programmes. Also, there is need to promote and/or create a conducive and enabling residential environment that would allow for full implementation of the principles of crime prevention through environmental design (territorial functioning, natural access, target hardening, surveillance, image management and maintenance among others). This could be facilitated through the establishment of crime prevention department that will give room for undertaking frequent researches in this respect.

It must be emphasised that checkmating property crime through effective implementation of the proposed model portends the benefits of good governance, increased government revenue through property tax, reduce cost of governance, removal of psychological effect of fear of crime/sudden death, increase efficiency of labour, boosting housing investment and enhancing housing and environmental sustainability, to mention only but a few.

This concept if fully implemented would only become a replica of what is being practiced in some other developed countries and continents like USA, UK, Canada, Australia, Europe and Asia where researches have shown that property crime has been kept at the lowest ebb.

\section{References}

Abdullah, A., Salleh, M. N. M., \& Sakip, S. R. M. (2012). Fear of crime in gated and non-gated residential areas. Procedia-Social and Behavioral Sciences, 35, 63-69.

Agbola T. (1997) The Architecture of Fear: Urban Design and Construction Response to Urban Violence in Lagos, Nigeria. Research Report, IFRA, Nigeria. http://www.openedition.org/6540.

Agunbiade, M. E. (2012) Land Administration for Housing Production. Being unpublished PhD Thesis submitted to the University of Melbourne, Australia.

Archer, K. J., and Lemeshow. S. (2006) Goodness-of-fit test for a logistic regression model fitted using survey sample data. Stata Journal 6: 97-105.

Armitage, R. and Pascoe, T. (2016) Crime Prevention through Environmental Design. In: Handbook of Crime Prevention and Citizen Security For Latin America. Ediciones Didot, Arévalo. Download version http://eprints.hud.ac.uk/26948/

Clarke, R. V (1992). Situational Crime Prevention: Successful Case Studies. Security Journal 1:143-148

Clarke, R. V. (1980) "Situational" Crime Prevention: Theory and Practice. The British Journal of Criminology, 136147.

Cleves, M. A., and A. Tosetto. (2000) Logistic regression when binary outcome is measured with uncertainty. Stata Technical Bulletin 55: 20-23. Reprinted in Stata Technical Bulletin Reprints, vol. 10, pp. 152-156. College Station, TX: Stata Press.

Cohen, M. A. (1990). A note on the cost of crime to victims.Urban Studies, 27(1), 139-146.

Cozens. P. M. (2014) Think crime! Using evidence, theory and crime prevention through environmental design (CPTED) for planning safer cities.Praxis Education: Publishers for professionals.

Cozens, P., \& Love, T. (2015) A review and current status of crime prevention through environmental design (CPTED). Journal of Planning Literature, 2015: 0885412215595440.

Crowe, T. D. (1991) Crime prevention through environmental design: Applications of architectural design and space management concepts. Revised by Lawrence J. Fennelly. Butterworth-Heinemann. First printed in 2000. 
Cullen, J. B., \& Levitt, S. D. (1999).Crime, urban flight, and the consequences for cities. Review of economics and statistics, 81(2): 159-169.

Dugan, L. (1999). The effect of criminal victimization on a household's moving decision*. Criminology, 37(4): 903930.

Fabiyi, O. (2004) Gated Neighbourhoods and Privatization of urban security in Ibadan Metropolis. IFRA. www.book.openedition.org/ifra/474. : Accessed on 11th June, 2015.

Federal Republic of Nigeria (2014) Annual report of the Federal Office of Statistics.

Gibbons, S. (2004). The Costs of Urban Property Crime*.The Economic Journal, 114(499), F441-F463.

Grabosky P (1995) Burglary prevention. Trends \& Issues in Crime and Criminal Justice no. 49. Canberra: Australian Institute of Criminology. http://www.aic.gov.au/documents/3 /5/D/\%7B35D86CDD-F1C5-4F1BBC85-378662CF6930\%7Dti49.pdf.

Grattagliano, I., Signorile, C., Lisi, A., De Rinaldis, M. F., Montedoro, M. A., Aliquo, G., ... \& Catanesi, R. (2015). Homeless Perpetrators and Victims of Crimes: Preliminary Findings of a Research in the Region of Puglia (Italy).International Journal of Criminology and Sociology, 4, 64.

Hastings, R. (2008) Achieving Crime Prevention: Reducing Crime and increasing Security in an inclusive Canada. Department of Criminology and Institute for the Prevention of Crime, University of Ottawa, Canada.

Hauck W. W. \& Donner, A. (1977) Wald's test as applied to hypotheses in logit analysis. Journal of the American Statistical Association 72: 851-853

Hosmer, D. W., \& Lemeshow, S. (2000). Introduction to the logistic regression model. Applied Logistic Regression, Second Edition, 1-30.

Jargowsky, P. A. (1996) Beyond the street corner: The hidden diversity of high-poverty neighborhoods. Urban Geography, 17(7): 579-603.

Jennings, D. E. (1986) Judging inference adequacy in logistic Regression. Journal of the American Statistical Association 81: 471-476.

Marzbali, M. H., Abdullah, A., Razak, N. A., \& Tilaki, M. J. M. (2012). Validating crime prevention through environmental design construct through checklist using structural equation modelling. International Journal of Law, Crime and Justice, 40(2), 82-99.

Massey, D. S. \& Denton, N. A. (1993) American apartheid: Segregation and the making of the underclass.Cambridge, MA: Harvard University Press.

Moreto W. (2010) Risk factors of urban residential burglary. RTM Insights 4: 1-3.

Naroff, J. L., Hellman, D. \& Skinner, D. (1980) Estimates of the impact of crime on property values. Growth and Change, 11(4):24-30.

Ngutu, J. A (2014) The Influence of poverty on crime among the Abanyole of Emuhaya district, Western Kenya. IOSR Journal of Humanities and Social Science 19(4) Ver.VII : 108-142

Olufolabo, O. O., Akintande, O. J. and Ekum, M. I. (2015) Analysing the distribution of crimes in Oyo State (Nigeria) using Principal Component Analysis (PCA). IOSR Journal of Mathematics. Vol. 11 Issue 3 Pp. 90-96.

Onibokun, A. (2003). Poverty and insecurity in Anglophone West Africa.Security, crime and segregation in West African cities since the 19th century, IFRA publication, 175-182.

Pallant, J. (2011) SPSS Survival Manual. A step by step guide to data analysis using the SPSS program. Allen \& Unwin, Australia. 4th Edition.

Pyke, S. W. \& Sheridan, P. M. (1993) Logistic Regression Analysis of graduate student retention. The Canadian Journal of Higher Education. Vol. XXIII-2

Ratcliffe J (2001) Policing urban burglary. Trends \& Issues in Crime and Criminal Justice no. 213. http://www.aic.gov.au/publications/current\%20series/tandi/201-220/tandi 213. aspx,

Ross, A., Duckworth, K., Smith, D. J., Wyness, G., \& Schoon, I. (2011). Prevention and Reduction: A review of strategies for intervening early to prevent or reduce youth crime and anti-social behaviour. Centre for Analysis of Youth Transitions, Department of Education. 
Olajide, S.E. \& Lizam, M. (2017). Proposed Socio-Environmental Design Factors (SEDEF) Modelas Residential Neighbourhood Crime Prevention Strategy in Nigeria. Advances in Social Sciences Research Journal, 4(1) 203-214.

Schwartz, A. E., Susin, S., \& Voicu, I. (2003) Has falling crime driven New York City's real estate boom? Journal of Housing Research, 14(1): 101-136.

Sutton, A., Cherney, A., \& White, R. (2013) Crime prevention: principles, perspectives and practices. Cambridge University Press.

The John Howard Society of Alberta (1995) Crime Prevention through Social Development: A Literature Review. Government Funded Research, www.johnhoward.ab.ca/ pub/pdf/C6.pdf, 1995. Accessed on 17th July 2015

Times International, London, November, 4, 1985.

Tita, G. E., Petras, T. L., \& Greenbaum, R. T. (2006) Crime and residential choice: a neighborhood level analysis of the impact of crime on housing prices. Journal of Quantitative Criminology, 22(4): 299-317.

Waller, I., and Weiler, D. (1985) Crime prevention through social development: An overview with sources. Ottawa: Canadian Council on Social Development.

Van Dijk J \& de Waard J. (1991) A two dimensional typology of crime prevention projects: With a bibliography. Criminal Justice Abstracts 23: 483-503. 